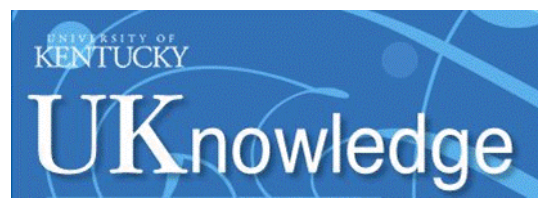

University of Kentucky

UKnowledge

7-1968

\title{
Economic Analysis of Alternative Flood Control Measures
}

\author{
L. Douglas James \\ University of Kentucky \\ Thomas M. Rachford \\ University of Kentucky \\ James Ray Villines \\ University of Kentucky \\ Clyde R. Dempsey \\ University of Kentucky \\ James Norris Cline \\ University of Kentucky
}

See next page for additional authors

Follow this and additional works at: https://uknowledge.uky.edu/kwrri_reports

Part of the Emergency and Disaster Management Commons, Natural Resources Management and Policy Commons, and the Water Resource Management Commons

Right click to open a feedback form in a new tab to let us know how this document benefits you.

\section{Repository Citation}

James, L. Douglas; Rachford, Thomas M.; Villines, James Ray; Dempsey, Clyde R.; Cline, James Norris; and Miller, Carlos Fix, "Economic Analysis of Alternative Flood Control Measures" (1968). KWRRI Research Reports. 177.

https://uknowledge.uky.edu/kwrri_reports/177

This Report is brought to you for free and open access by the Kentucky Water Resources Research Institute at UKnowledge. It has been accepted for inclusion in KWRRI Research Reports by an authorized administrator of UKnowledge. For more information, please contact UKnowledge@lsv.uky.edu. 


\section{Authors}

L. Douglas James, Thomas M. Rachford, James Ray Villines, Clyde R. Dempsey, James Norris Cline, and Carlos Fix Miller

This report is available at UKnowledge: https://uknowledge.uky.edu/kwrri_reports/177 


\title{
ECONOMIC ANALYSIS OF ALTERNATIVE \\ FLOOD CONTROL MEASURES
}

\author{
Dr. I. Douglas James \\ Principal Investigator

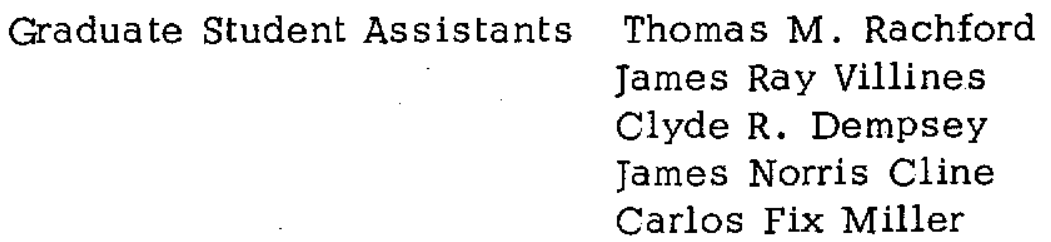

The work upon which this report is based was supported in part by funds provided by the United States Department of the Interior, Office of Water Resources Research, as authorized under the Water Resources Research Act of 1964 . -

Project Number A-001-KY (Completion Report)

Agreement Number 14-01-0001-1085 (FY 1968)

Research conducted from May, 1965, through June, 1968

University of Kentucky, Water Resources Institute

Lexington, Kentucky

July, 1968 
PREFACE

This research report serves as a technical completion report for a project by the same name sponsored by the University of Kentucky Water Resources Institute and financially supported for the most part by funds provided by the United States Department of the Interior as authorized under the Water Resources Research Act of 1964. Some financial help was also provided by the University of Kentucky Research Foundation.

Special thanks must also be extended to the Louisville District Office of the U.S. Army Corps of Engineers, the U. S. Geological Survey, and the U.S. Weather Bureau for help in data gathering. The staff of the University of Kentucky Computing Center was most helpful in helping solve the many problems encountered in program development. The total technical completion report includes in addition to this general summary report the reports by the five graduate student assistants listed on the title page and referenced in the List of Project Publications. The reader interested in a more detailed description of project findings should consult this additional material. 


\section{ABSTRACT}

Within the last few years, the growing realization that an effective flood control program must include non-structural measures (land use management and flood proofing) has resulted in Presidential Executive Order 11296 requiring Federal agencies to seek the optimum combination of structural and non-structural measures for flood control. The requirement has created a dilemma. No methodology is available for systematic evaluation of alternative combinations of structural and non-structural measures. Prospective procedures are too time consuming to be feasible under current financial and manpower limitations.

The only way out is to perform much of the planning process by digital computer. With this goal, two flood control planning programs have been developed. Each program systematically selects the optimum combination of channel improvement, flood proofing, and land use management by location within the flood plain and by time. The second program adds detention storage to the list of available alternatives. Both programs contain the entire planning process by going all the way from raw data to a selected optimum program of measure use in one run. However, the programs are not intended to produce a finished design. Their use should be followed by a final field check to verify the input data and preparation of the plans and specifications necessary for implementation.

The programs have been applied to a series of flood hazard areas in California and Kentucky and indicated an optimum flood control program in a small fraction of the time spent in current planning methods. They free the planning engineer from spending most of his time in routine calculations and allow more time for consideration of qualitative and intangible factors. 
TABLE OF CONTENTS

\begin{tabular}{|c|c|}
\hline & Page \\
\hline PREFACE & iii \\
\hline ABSTRACT & $\mathrm{v}$ \\
\hline INTRODUCTION & 1 \\
\hline RESEARCH OBJECTIVES & 5 \\
\hline PROGRAM DEVELOPMENT & 6 \\
\hline Significance of Selected Measures & 7 \\
\hline Division into Planning Blocks & 8 \\
\hline Optimizing Planning Block Measures & 10 \\
\hline Cost of Structural Measures & 10 \\
\hline Cost of Flood Proofing & 11 \\
\hline Cost of Land Use Management & 13 \\
\hline Cost of Flood Damage & 14 \\
\hline The Search for the Optimum Combination & 17 \\
\hline The Storage Alternative & 18 \\
\hline Economic Justification & 18 \\
\hline Dam and Reservoir Design & 19 \\
\hline HYDROLOGIC STUDIES & 20 \\
\hline Flood Peaks & 20 \\
\hline Unit-Area Flood Peaks & 21 \\
\hline Area Factors & 23 \\
\hline Urbanization and Channelization Factors & 24 \\
\hline Flood Hydrographs & 26 \\
\hline The Stanford Watershed Model & 27 \\
\hline PROGRAM APPLICATION & 28 \\
\hline Potential Applications & 28 \\
\hline Design Standards & 28 \\
\hline Sensitivity Studies & 29 \\
\hline
\end{tabular}


Research Guidance

Property Owner Guidance $\quad 30$

Local Government Guidance $\quad 30$

A Planning Tool 30

Application Experience 31

Morrison Creek Watershed, Sacramento County,
California

Pond Creek Watershed, Jefferson County, Kentucky 31

Licking River Watershed, Harrison County, Kentucky 32

North Fork of the Kentucky River Watershed, Perry County, Kentucky 32

Sensitivity Studies 33

RESEARCH NEEDS $\quad 34$

PROGRAM AVILABILITY 36

CONCLUSION 38

LIST OF REFERENCES

List of Project Publications 39

List of Major References $\quad 40$

List of Other Related Publications 41 


\section{INTRODUCTION}

Those responsible for the legislation which in 1936 gave national scope to the Federal program of constructing structural measures for flood control recognized the nation should not construct a reservoir, flood wall, or channel improvement to protect everyone subject to flood damage. A criterion for selecting worthy projects was needed. Logic indicated the decision should have something to do with the amount of flood damage and the cost of remedial measures. Therefore a selection criterion based on a comparison of benefits and costs was written into the legislation. Certainly, a project must be worthwhile if it helps more than it costs. Thus, the test for economic feasibility was inaugerated.

At first, few appreciated the full implication of building only those projects reducing expected flood damage by an amount exceeding installation cost. A flood control project was conceived as a fixed unit. For example, a specific reservoir would be designed. Its installation cost would be estimated. Floods would be routed through the reservoir to determine the extent of flooding and hence flood damages with and without the facility. The effected reduction in the expected value of the damages would be taken as the benefits. A straightforward benefit-cost comparison would then be available as a basis for acceptance or rejection of the project.

However, computing benefits and costs turned out to not be all that easy. Difficulties are caused by problems of quantity and problems of value. Quantity problems include predicting flood peak by frequency, area and depth of flooding by peak, and damageable property within the flood plain by time, place, and kind. Hydrologic probabilities cannot be established and economic development in the 
flood plain cannot be predicted with absolute certainty.

Value problems arise in stating the damage caused by a contact between property and flood water. The damage includes the cost of repairing, renabilitating or replacing the property plus more intangible effects on transportation, employment, health, security, etc. Floods change the lives of people, all kinds of people in many varying degrees. Many of these effects are difficult or impossible to express in the same dollar units used to measure installation cost.

Both types of measurement problems may be approached through sensitivity studies. One may not know a value for certain, but often he can predict a probable and a range of possible values. The analysis may be repeated for high and low values within this range. If variation does not affect economic feasibility, the project is not sensitive to that variable. If it does, the range of variation indicating a feasible project and the range indicating an infeasible one may be determined by repeating the analysis for intermediate values within the range to help guide the final decision.

Project planning based on fixed quantities and unit values is unrealistic. Project planning considering the sensitivity of economic feasibility to alternative possible values requires a long series of repetitious calculations. Budget and manpower limitations frequently severely limit thorough analysis.

Furthermore, many little choices must be made in project design. Any structural measure can be constructed bigger or smaller, sooner or later, here or there, by this method or that method. Larger channels may be built to reduce the required reservoir storage. The criterion for determining overall project justification must be extended to selecting the nature of the best project design.

Some design choices do not appreciably affect benefits. Lined or unlined channels may be built to the same capacity. The logical 
choice between the two would be according to least cost.

Other choices affect benefits. Extending channels further upstream increases benefits. It also increases cost. The logical interpretation of the project selection criterion would be to consider the extension a little project to be justified on the basis of incremental benefits versus incremental cost. As a coroliary, the best project design has the maximum benefit net of cost. Planning the best design thus also requires a long series of repetitious calculations Benefits and costs must be computed for many alternative combinations of measures.

At its best, the planning of structural measures for flood control requires comparison of many alternatives. The agencies are charged to consider many sizes of reservoir, locations of reservoir, degrees of channel improvement by location, locations where channel improvement may or may not be implemented, and times when individual project elements may be built or enlarged (2H). Planning is a very complicated and time consuming process. Several years are normally spent in the analysis, and even then there is no assurance that the best combination has been found.

As complicated as this procedure is, it is inadequate. A measure not considered cannot be included in the optimum policy. The traditional analysis ignores non-structural alternatives. Maybe damage prone property should not be locating in the flood plain. Maybe action by individual property owners would be the most effective measure. To remedy this omission, Federal agencies have recently been required by presidential order to determine what is and what is not economic use and development of the flood plain (2G). More recently, The Office of the Chief of Engineers has required all District Offices to begin investigating all appropriate non-structural alternatives $(3 \mathrm{C})$.

The requirement produces a twofold problem. How can the benefits and costs from non-structural measures for flood control be 
estimated? How can already overworked planning agencies cope with a much more complicated analysis when they can scarcely keep pace with planning structural measures?

A quick review of the scope of the new requirement helps convey the magnitude of the problem. How does one determine the cost of restricting flood plain development? What is the cost in each part of the flood plain? How will it change throughout project life? From how much of the flood plain should development be excluded? Which kinds of development should be excluded? How can individual owners protect their property by flood proofing? What is the cost of each method? How does it vary among types of property? Many more questions might be added.

The new requirements have added a large number of new alternatives to those which must be considered (2G). The benefit maximizing criterion is still to be used to select the best $(2 \mathrm{H})$. The analysis of non-structural measures must be brought into the benefit cost framework.

Water resources planners look to three disciplines for help. They look to economics for help in devising better procedures for evaluating benefits and costs. They look to operations research or systems analysis for more efficient ways to systematically search the available alternatives with reasonably good prospects of truly determining the best. They look to computer science for programming the tedious repetitive computations needed to execute the new techniques. Knowledge developed by many disciplines must be combined in formulating a workable planning approach.

In many ways, project planners have been slow to realize the full potential of the digital computer. It is being used to execute much more quickly and accurately the calculation techniques for years performed manually. However, the digital computer opens the door to 
numerical methods which heretofore could not even be attempted. The computer can be used to integrate project components into a comprehensive flood control program as well as execute a more thorough analysis of its every component as is now being done. Quickly executed sensitivity studies prepare the way for resolving the more controversial variables by establishing the consequences of alternative choices.

\section{RESEARCH OBJECTIVES}

The basic objective of this research has been to show by example how the digital computer can perform the repetitive computations inherent in flood control planning and thus make possible detailed economic analysis of many alternative combinations of structural and non-structural measures. More effective use of the computer will permit planners to spend more time in and provide better information for resolving knotty extra economic considerations, provide a mechanism for selecting the sorely needed balanced program of structural and non-structural measures, and speed project planning to provide the decision makers with a wider selection of alternatives and to promote earlier construction of worthy projects.

As initially conceived, the specific research objective was to combine the procedures developed at the University of Chicago for estimating the benefits and costs from flood proofing (2F) and the procedure developed previously by the principal investigator for estimating the benefits and costs from land use management (2C, pp. 4451) with the traditional procedures for planning channel improvement and reservoir construction into a single computer program. This program was then to be used to establish the settings most favorable to each flood damage reduction technique and to test the sensitivity of the results to such debatable input variables as discount rate, urban growth projections, the value of urban open space, the flood 
frequency relationship in a changing urban environment, and unit costs.

Each of these objectives was achieved. The results have been published in five reports, one completed by each graduate student working on the project $(1 \mathrm{~A}, 1 \mathrm{~B}, 1 \mathrm{~F}, 1 \mathrm{G}, 1 \mathrm{H})$ and in three articles (1C, 1D, lE) by the principal investigator. The reports contain over 800 pages describing the development, nature, and application of the computer program. Manifestly, this summation report cannot repeat these findings in detail. Rather, the purpose here is to summarize the major results, tie the diverse studies together, and demonstrate the value of computerized project analysis as a practical tool for flood measure planning by responsible agencies.

The research led into the analysis of topics related to program development but not foreseen at the outset. Such topics included an analysis of whether right-of-way required for structural measures should be purchased at the time of construction or much earlier when costs may be lower (ID). The right-of-way holding study became necessary when it was found that the optimum project timing often specifies an earlier date for right-of-way purchases than for construction. Also included was a study of how to determine the floodfrequency relationship as a function of watershed characteristics and climatic setting (lF).

\section{PROGRAM DEVELOPMENT}

The search for the combination of flood control measures producing the maximum net benefit may be alternatively viewed as a search for the combination associated with the minimum net flood cost (2C, pp. 42-43). The minimum cost approach considers floods as creating a cost which may be borne by (1) suffering damages as they occur, (2) building reservoirs or channels (structural measures) to reduce the severity or frequency of flooding, (3) restricting flood 
plain development so less damageable property is located on the flood plain or (4) flood proofing flood-plain development to make it less susceptable to damage when it comes in contact with the water.

\section{SIGNIFICANCE OF SELECTED MEASURES}

Applying the economic efficiency criterion of minimizing cost to find the optimum combination of measures does not infer any particular method of measure implementation. Ideally, a perfectly functioning market would achieve the optimum mix of measures without interference from a central planning agency. People would suffer damage only when every alternative course of action was more expensive. They would join to build structural measures when they could do so by contributing an amount less than the damage they would otherwise suffer. They would withdraw from flood plain locations when they found expected damages to exceed the value of the land to them. They would flood proof their individual properties in whatever way they could as long as the expense of the effort did not exceed the effected damage reduction.

For a number of practical reasons, the optimum combinations of flood control measures is not likely to result from real-world economic forces. Flood control is a classic example of a public good. Floods occur too infrequently for the market to adjust to an equilibrium. Flood-plain dwellers do not adequately comprehend their decision alternatives.

The job of the planner is to objectively determine the optimum combination of measures. If the optimum should be automatically realized by the market (this may well be the case for certain nonstructural measures), no explicit implementing action is required. Otherwise (more usually the case), more detailed data should be collected to verify the findings and prepare the necessary construction plans and specifications for structural measures and the zoning 
regulations, building codes, or other methods used to implement non-structural measures.

\section{DIVISION INTO PLANNING BLOCKS}

At any given time and location within the flood plain, the optimum combination of flood control measures will minimize the sum of the four costs. The optimum changes with time as changes in the tributary watershed alter the flood threat and the pressures of urban development favor more intensive flood plain land use. The optimum will vary with location according to local flood plain and channel conditions and available upstream reservoir sites.

Theoretically, the optimum combination varies in a continuum over time and space. However, analysis of discrete segments is more practical. The space variation is best handled by dividing the total watershed into subwatersheds as nearly homogeneous as possible. The time variation is best handled by dividing the project life into stages.

However, the optimum measures within individual planning blocks cannot be selected without recognizing interblock interaction. Measures implemented in one subwatershed affect downstream flooding. Measures implemented in one stage change the initial conditions for the course of action in later stages.

Measures taken in one block may affect flooding in other blocks in many ways and to many degrees. Some effects are too small to warrant detailed analysis. Others have a pronounced effect on the optimum flood control policy. In programming the block analysis, the decision on explicit analysis of specific effects was based on whether the improved results seemed to justify the extra computer time. The primary interaction among subwatersheds was the increase in downstream flood peaks and hence flood cost caused by upstream channel improvement. This downstream cost was 
was estimated before the program selected any channel improvement, and the improvement was not considered justified unless the reduction in flood cost within the subwatershed more than exceeded the increase in flood cost downstream. A minor interaction among subwatersheds would result from the reduced upstream urbanization associated with land use management, but the flood plain is generally such a small portion of the total tributary watershed that this effect was not quantitatively analyzed.

Decisions made in one stage may profoundly affect alternatives available in a subsequent stage. A stage by stage analysis matching flood control measures to currently existing watershed conditions must be careful not to reject a slightly less favorable combination of measures in one stage that precludes a much more highly favorable combination in the next stage. Flood-plain development allowed in one stage cannot reasonably be subsequently removed. The opportunity for relatively inexpensive channel improvement in an uncongested environment is lost once the area is developed.

Several time effects are particularly important. The optimum timing of right-of-way purchase is not the same as the optimum time of construction (ID). Construction timing is governed by current need for flood control measures while right-of-way purchase timing is influenced by the probability of expensive development entering the required land before construction can be justified. Within the computer program, construction timing is governed by currently expected damages while right-of-way purchase timing is based on whether the value of the land preserved for construction of future structural measures exceeds its value in alternative uses (1D, p. 245).

Another timing issue is the need to restrict urban development from the beginning if it can later be economically justified 
rather than waiting until flood plain encroachment limits measure effectiveness. The problem of early flood-plain encroachment was met by developing a per acre cost of land use restriction which was a monotonially increasing function of urbanization (1A, p. 27). Thus land use regulation was unlikely to prove optimum in a later stage after being rejected in an earlier stage (except in cases where rejection is because there is no threat of urban encroachment even in the absence of any restriction).

\section{OPTIMIZING PLANNING BLOCK MEASURES}

The cost minimizing objective as it was applied to each spot in planning space and time was expressed mathematically as

$$
\mathrm{C}=\mathrm{C}_{\mathrm{S}}+\mathrm{C}_{\mathrm{p}}+\mathrm{C}_{1}+\mathrm{C}_{\mathrm{f}}
$$

where the total cost to be minimized (C) was subdivided into the four components: the flood damage $\left(\mathrm{C}_{\mathrm{f}}\right)$, the cost of structural measures $\left(C_{s}\right)$, the cost of flood proofing $\left(\mathrm{C}_{p}\right)$, and the cost of land use restriction $\left(C_{1}\right)$. The equation was applied by evaluating each of the four terms for alternative combinations of measures and alternative levels of protection provided by each measure.

Cost of Structural Measures: The two basic types of structural measures are channel improvement and detention storage. Channel improvement benefits the planning block. Detention storage benefits a long string of downstream planning blocks. Thus planning detention storage cannot be handled by analysis of the individual planning block but rather requires a more complicated multiblock analysis.

Structural measures within the planning block serve to increase channel capacity. For major rivers, the improvement generally consists of levees or flood walls to raise the banks around specific damage prone areas with minimum disturbance to the main channel section. The computational framework programmed for computer analysis is based on smaller channels where a straight prismatic 
channel is built to replace the irreguiar natural section on a sinuous alignment.

The type of prismatic channel best suited to a particular location is primarily determined by the soil stability, cost of right-of-way, and hydraulic gradient. Channels located in erosion resistant soils on flat gradients in areas of low right-of-way cost are least expensive when an unlined earth section is used. A more erodable soil requires drop structures or in more extreme cases a pneumatically lined trapezoidal section. High right-of-way cost makes a lined trapezoidal and in more extreme cases a reinforced concrete rectangular cross section more economical. The computer analysis compares the cost of each channel type through a cost estimate based on construction quantities and unit costs for each planning block and determines the least cost alternative for each case (1G, pp. 64-71).

It may be economical in some cases to improve a channel in one stage and further improve it in a later stage. The cost of further improvement is estimated from construction quantities and unit costs with a fixed cost added. Once a channel improvement of a given type has been implemented in one stage, the type is not changed with enlargement in a subsequent stage except where drop structures become required or pneumatic lining of an existing section is found less expensive than buying more right-of-way and enlarging the channel. Cost of Flood Proofing: Flood proofing includes measures employed on an individual or small group basis to lessen flood damages by emergency action immediately prior, during, or immediately following a flood; use of special flood-damage resistant construction materials; or structural changes (raising the floor elevation or making the structure water tight) to keep water from entering buildings.

A property owner may employ any number of many variations in courses of emergency action, building materials, or structural changes. From the purely economic standpoint, the choice should be governed by 
the frequency and severity of flood damage and the cost of the flood proofing measures. In reality, the conception the property owner has of the flood hazard and the extra economic disutility he places on flood damage often are the primary factors governing the flood proofing measures employed ( $3 B$ ).

Experience has shown the degree to which property owners employ flood proofing to increase with the frequency and severity of flooding. The extent of flood proofing tends to relate to flood frequency by a relationship of the type shown on Figure 1. Somewhere around the 35 -percent event (1C, p. 340) is the breakpoint between where flood proofing can be economically widely used and where only scattered application to high valued property can be justified. The computer analysis is designed to select those areas where widespread flood proofing can be justified. The selection and design of the final measures is the next step.

The key to formulating an effective flood proofing program is more detailed information on the effectiveness of particular procedures in damage reduction. The laboratory for obtaining such information is areas now subject to frequent flooding. Many peaple in such areas have evolved a working procedure for living with frequent flooding while suffering minimum damage. Therefore, a foot of water in a building flooded annually is not found to cause the same damage as the same water entering a similar building only very rarely. Much more study is needed before an economically efficient flood proofing program can be evolved.

In the computer analysis, the cost of flood proofing is handled as a linear function of the depth of the design flood and the market value of the structure. The linear coefficient may be varied according to measures appropriate to the given local situation (1A, pp. 115-117). 


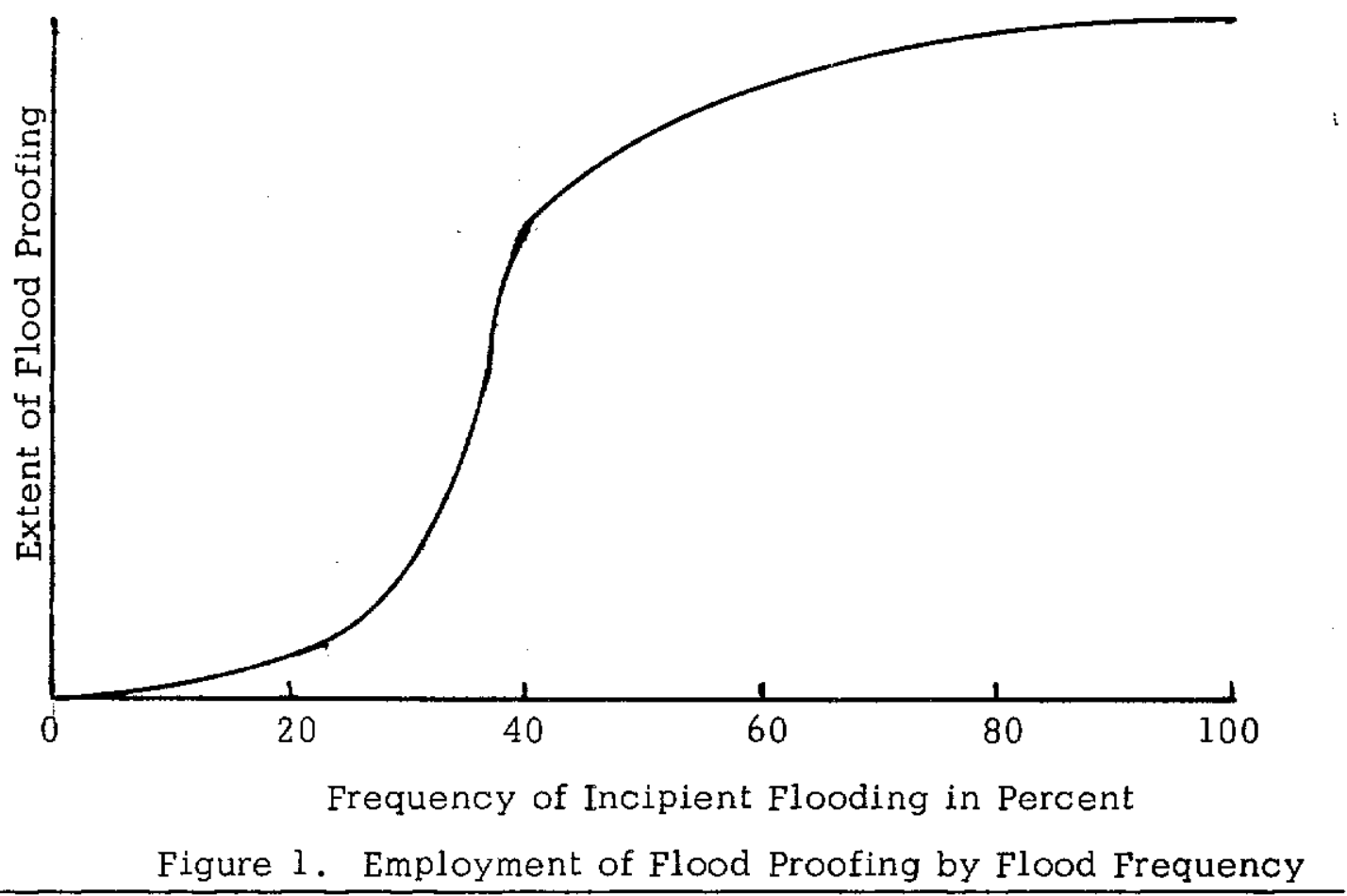

Cost of Land Use Management: One way to reduce flood damage is to refrain from locating damage susceptable property in the flood plain. Property owners aware of the flood hazard will not develop flood-plain land if the expected damage exceeds the value they expect to realize from the development. To the degree the interest of the property owners, does not conform to that of the community or the general public, landuse management by a governmental agency through zoning or other controls may be necessary. The difference in interest would generally stem from private developers expecting the public to bear flood damage costs or from the value of preserving urban open space which accrues to the community as contrasted to the individual owner.

Other factors being equal, experience has shown frequently flooded areas to be characteristically less developed than higher ground. The restriction to flood-plain development may be related to flood frequency by the same type of relationship used for flood proofing on Figure 1. 
Property subject to severe flood damage is unlikely to be found even in areas of low flood hazard. Each property type will have some level of flood hazard at which it can no longer economically locate in the flood plain. One might, for example, expect a progressively greater hazard tolerance in going from schools to homes to industry to parking lots to agriculture to parks. The computer analysis is designed to select those areas where average urban development is unwise. It has not been refined to differentiate among individual urban development types.

In the computer analysis, the cost of foregoing urban development and hence preserving agricultural development commensurate with the flood hazard is computed as a function of the cost of establishing and enforcing land-use regulation $(\mathrm{E})$, the value of the land for urban development (I $)_{u}$, the value of the land in agricultural use (I $a$ ), and the esthetic value of preserving the land as open space (or recreational space) in an urban area $\left(\mathrm{I}_{\mathrm{p}}\right) . \mathrm{E}_{\mathrm{C}}$ increases with urban development because of mounting political pressure to permit development of open land in an otherwise highly developed area. However, the effect is not brought into the computer analysis because data is scarce and the optimum planning program is probably relatively unsensitive. Ia decreases with more intensive surrounding urban development because of the greater difficulty of farming in an urban area. Provision for this relationship is made in the input data ( $1 A, p .92) . I_{u}$ and $I_{p}$ both drastically increase as alternative open land becomes more scarce, a change also included in the computer analysis $(1 \mathrm{H}, \mathrm{pp} .28-29,146-$ 147). With all four of these values estimated,

$$
\mathrm{C}_{1}=\mathrm{E}_{\mathrm{C}}+\mathrm{I}_{\mathrm{u}}-\mathrm{I}_{\mathrm{p}}-\mathrm{I}_{\mathrm{a}}
$$

Cost of Flood Damage: Flood damages accrue to development on the flood plains. They are best estimated by dividing the development between crops and structures. The crop damage per unit area caused 
by a given flood may be characterized as a fixed damage caused by the fact of flooding plus an incremental damage per foot of flood depth. The two damage factors are governed by the crops being grown and the time of the year of flooding. The crops grown depend on the quality of the soil. The computer analysis is based on read values of fixed and incremental damage (for up to three soil quality ranges) which must be determined from analysis of local cropping patterns and seasonal flood hazard (1A, pp. 84-92).

The damage to structures from shallow flooding is estimated as a linear function of the depth of the flood and the market value of the property. The coefficient is read and should be varied according to prevailing local conditions of flood duration, velocity, sediment content, and season. It may also be adjusted as desired to include indirect and secondary damages provided these can be estimated as a constant percentage of direct damages. The market value of the property in average dollars per acre is also read. Either the value of structures alone or the value of structures plus contents may be used with the appropriate damage coefficient. The linear coefficient is reduced by one half for additional depths once the damage exceeds 25 percent of the market value. A ceiling is set to maximimize damage at 75 percent of the market value (1H, pp. 29-34).

In addition to the total damage caused by the flood water to crops, structures, and contents, some may wish to include an uncertainty damage associated with aversion to suffering large losses in an irregular and unpredictable pattern. Most people would be willing to pay an annual flood damage bill exceeding their average annual loss to be free from the threat of catastrophic flood loss. This excess is estimated within the program through use of the Thomas Uncertainty Fund (1A, pp. 8-10). A low level of flood protection may reduce expected damage while increasing uncertainty damage by producing a more irregular damage pattern. Consideration of 
uncertainty damages provides a mechanism for introducing this effect into the planning optimization.

Damages residual to flood control measures are estimated by the same method used to evaluate the basic damages. Flooding residual to structural measures are assumed to relate to flood peak less channel capacity according to the same relationship which exists without the measures. Damages residual to flood proofing are assumed to be 11.1 percent of those to structures not flood proofed (damage to landscaping and outsides of buildings) and to be their full value with no flood proofing, for crops, or when the design flood is exceeded. Damages residual to a landuse limitation are considered to accrue only to preexisting development in the restricted area and to accrue to full unrestricted development outside (1G, pp. 62-63).

The estimation of flood damage is complicated by the functional relationship between flood-plain development and the level of flood protection provided by structural measures. Provision of flood protection corresponds with some set of initial flood-plain development conditions. Certain changes would occur through the years even if no structural measures were provided. The development may become either more or less intensive depending on the local economy and the changes tributary watershed development causes to the flood hazard. Benefits to this development may be legitimately used for measure justification.

If structural measures are provided, additional development will occur. Some development which would not locate within the flood plain without the provided protection can now economically do so because of the reduced risk. Some benefit to such development, the amount depending on the risk level at which the development can economically enter the flood plain, can be used for measure justification. Total benefits would equal a land enhancement benefit associated with more intensive development (estimated as a reduction in land 
use management cost in the computer analysis) plus the benefit realized between the level of risk at which the development can enter the flood plain and the level of risk residual to the measures.

Finally, some development is attracted into the flood plain by a false sense of security stemming from overconfidence in project effectiveness. Prevention of damage to such development is not a legitimate project benefit.

In the computer analysis, projected flood plain development is read as part of the input data. Ideally, development should be projected on the basis of no flood hazard. The program determines when and where lesser development is more economical because of the flood hazard.

The increased flood-plain development induced by structural measures should be considered in planning the level of protection to be provided (3D, pp. 46-55). The result is a higher level of protection than could otherwise be found justified. The program can be used either way by varying the input control options (1A, pp. 57-62). However, the increase in optimum level of protection by structural measures was not found to be great in the case studies. The Search for the Optimum Combination: As decision alternatives within a given planning block, combinations of three measures are available over a continuum of possible design frequencies. Again, the analysis requires discrete choices in the form of up to ten possible design frequencies specified for consideration in the input data. The search procedure is basically an exhaustive comparison (1H, pp. 44-50; lG, pp. 53-58). The cost (summed from Eq. 1) is first estimated for no measures being used at all. Then flood proofing to increasing levels of protection is tried until further flood proofing increases the total cost (C) above that for the previously tried level. The search is immediately terminated if $C_{p}$ alone is found to exceed the total cost with no measures applied. Any combination found to 
have less total cost (C) than any tried previously is saved as a possible optimum. Land use adjustment is then analyzed in the sequence of increasing level of protection first alone for each frequency and then in conjunction with each potential level of flood proofing. Lastly, channel improvement is considered for monotonically increasing channel capacities in the sequence of alone, supplemented by flood proofing, supplemented by land use adjustment, and supplemented by both. Naturally, only levels of protection provided by the non-structural measures exceeding those provided by the structural measures need be considered. With the search completed, the program has saved the optimum combination of the three measures (each specified by design flood frequency) for the particular planning block in time and space.

THE STORAGE ALTERNATIVE

The major structural alternative not considered in the planning block analysis is reservoir storage. It must be considered separately because it reduces flood damage not within the tributary area but rather downstream.

Economic Justification: The analysis of storage benefits is based on flood hydrographs with and without flood control storage. The hydrographs flowing past the reservoir site for three selected frequencies (200-year, the design frequency, and mean annual) are routed downstream from one planning block to another until the lower boundary of the study area is reached. The routed hydrograph is combined with the local inflow hydrograph for each planning block, and the flood peaks are used to derive the appropriate relationship between flood peaks and frequency $(1 \mathrm{H}, \mathrm{p}, 41)$. This relationship is then used as the basis for selecting optimum planning block measures.

If the above procedure is performed twice, once each for two reservoir storage totals, one has a minimum cost combination of 
measures for each planning block for each storage total. The incremental increase in storage is justified if it costs less than the resulting reduction in total cost summed for all downstream planning blocks. Provision is also made in the input data for reading and including in project justification benefits accruing downstream from the area analyzed in detail .

The optimum flood storage is established by first performing the analysis with no storage (other than that specifically allocated to other project purposes) and then examining progressively larger flood storage totals specified by frequency for incremental justification. The greatest storage whose last increment is justified is optimum as long as the total storage is justified as well. The analysis terminates if successive increments are producing progressively less net benefit. Dam and Reservoir Design: Reservoir design is based on inflow hydrographs developed from input hydrological data, stream flow at the beginning of the design storm hydrograph as estimated on a probability basis from read cumulative runoff data, and read data describing reservoir geometry. Sediment storage is based on a read rate of annual sediment inflow. Storage for purposes other than flood control may be specified in the input data, but its economic justification is not evaluated by the program. The elevation of the rightof-way purchase line with respect to the dam top is read in the input data.

The dam includes a principal spillway to handle floods smaller than that for the design frequency and an emergency spillway to handle larger floods. The principal spillway is a closed conduit, and the emergency spillway is a straight open channel chute. The principal spillway is sized based on a data prescribed drawdown period and cumulative runoff data. Required flood storage is determined by reuting the design flood through this principal spillway beginning with the initial stream flow. The sizes of the dam and 
and emergency spillway are based on routing a large flood determined as a data specified multiple of the 200-year hydrograph. The emergency spillway width is selected internally within the program to minimize dam and reservoir cost. Either abutment or side saddle locations may be used.

The dam design and cost analysis is based on an earth section protected by riprap on the upstream face and placed over an impervious trench for seepage control. However, a concrete gravity section or a rock section with an impervious blanket on the upstream face may be handled by adjusting the input data. Quantities are calculated based on read geometric structural, hydraulic, and hydrologic data following much the same procedures traditionaly used in dam design. Separate designs, quantities, and cost estimates are made for the dam embankment, the emergency spillway with an hydraulic jump type stilling basin, the principal spillway with an impact energy dissipator, reservoir clearing, right-of-way, and relocations. All costs are converted to discounted average annual values over the project life for the optimization analysis.

\section{HYDROLOGIC STUDIES}

Flood damages are estimated through the flood frequency relationship. Hydrologic studies are a critical component of the economic analysis. The flood frequency relationship must be determined for every subwatershed during each stage. This can only be accomplished by a method capable of predicting flood peaks (and flood hydrographs where storage routing is required) as a function of drainage area and the degree of urban development and channel improvement in the tributary area.

\section{FLOOD PEAKS}

A direct functional relationship may be used when only measures within the planning block are to be employed. For a 
natural drainage area, one containing neither urban development nor improved channels, the flood peak may be estimated as the product of the flood peak from a typical one-square-mile area, the size of the tributary area, and a factor relating flood peak in cubic feet per second per square mile to drainage area.

Both the flood peak per unit area and the peak-area relationship vary with frequency. If both values are known for two frequencies (the mean annual and 200-year events are used in the computer analysis), the flood peaks for both events may be estimated for any point in the planning area.

The flood peaks predicted for the two frequencies can then be used to estimate the flood frequency relationship. Interpolation using Gumbel extreme probability theory is used in the computer analysis because of the simplicity of the functional relationship for use in repeated calculations. However, any desired approach may be used to estimate the 200-year flood peak from available hydrologic information. The Gumbel relationship controls interpolation for intermediate flood peaks only.

The approach assumes individual small natural areas in the watershed are relatively homogeneous: the peak from a natural area of any given size is relatively constant among the different portions of the total watershed. If equal areas cannot be represented by the same flood peak, subwatershed areas read in the input data may be adjusted to "equivalent" areas producing the desired peak. Unit-Area Flood Peaks: The ideal data for estimating unit-area flood_peaks would be a long-term gaged record on a one-squaremile watershed typical of all the other watersheds of that size in the study area. Without this information, the peak must be estimated in one of two other ways. If long-term records are available for nearby básins having similar watershed surface conditions and representing a wide range of drainage areas, each record may be 
used to estimate the mean annual and 200-year flood peaks. These may then be plotted versus drainage area to develop the peak-area relationship: Peaks for one square mile may be read from the curve. More generally, a sufficient number of long-term records to derive such a relationship will not be available representing the vicinity of the study area, and the flood peak from the one square mile natural drainage area must be estimated from watershed and climatic information. The Stanford Watershed Model (2B) was employed to provide a general procedure for estimating the peak

Flood peaks from small drainage areas have long been estimated by use of the rational formula.

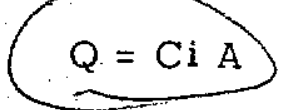

where $Q$ is the peak streamflow in cfs, $i$ is the peak rainfall intensity in inches per hour lasting for the basin time of concentration, and $C$ is a runoff coefficient which would equal one if the peak rate of streamflow equalled the peak rate of rainfall. $Q, C$, and i should be visualized on a frequency basis. The runoff coefficient relates the runoff peak to the rainfall event of the corresponding frequency and does not necessarily apply to any historical storm. Its magnitude is not constant for storms of different magnitude on a given watershed nor for watersheds of equivalent surface characteristics subject to different rainfall amounts and storm patterns.

The value of $\mathrm{C}$ is less than one for two basic reasons. Some of the moisture is lost to direct runoff by evapotranspiration and infiltration. Some of the runoff is delayed by temporary channel storage; true equilibrium conditions are never really established during real storm patterns over natural areas. By separating these two effects, $\mathrm{C}$ may be estimated as the product of $\mathrm{C}_{\mathrm{o}}$ and $\mathrm{C}_{\mathrm{r}}$.

The overland flow coefficient $\left(\mathrm{C}_{\mathrm{o}}\right)$ from a natural area depends on the soil moisture storage capacity, the soil permeability, the soil surface slope, the nature of the soil surface, the antecedent moisture, 
and the rainfall intensity. The last two independent variables are those causing the runoff coefficient to vary with climate and with frequency. Using the Stanford Watershed Model (2B) and studies made by the Kentucky Department of Highways (2A) a procedure was developed for estimating $\mathrm{C}_{\mathrm{o}}$ from parameters indexing basin wide average values of the listed independent variables (lF). The procedure uses a coaxial correlation to determine the coefficient for a particular soil surface and adjustment factors indicating how the coefficient varies with prevailing rainfall amounts and intensities as well as frequency. The storage routing coefficient $\left(\mathrm{C}_{\mathrm{r}}\right)$ for natural channels depends upon channel storage, alignment configuration, and slopes. A derivation of a general relationship was not in the scope of this research but values of 0.5 were found to work well for two typical one square mile watersheds, one in California and the other in Kentucky (1B, p. 66). By applying the product of $\mathrm{C}_{\mathrm{r}}$ and $\mathrm{C}_{\mathrm{O}}$ as $\mathrm{C}$ in $\mathrm{Eq} .3$, a reasonably accurate unit area flood peak was found.

Area Factors: The relationship between flood peak and drainage area depends on the distribution of watershed surface characteristics and channels throughout the tributary area. For example, proceeding downstream through a typical basin, one may go from steeper slopes to flatter valley land. The flatter slopes should dampen flood peaks. The effect would reduce the area factor for the larger basins extending into the flatter land.

Thus, a particular peak-area relationship is more or less unique to specific watershed. The larger areas typically apply only to one particular point on the stream. A factor representing conditions tributary to that point should be used. As one goes along the curve to smaller areas, two, three, and progressively more drainage areas are represented by a common point. The factor for any particular drainage area size should reflect average conditions among these areas. Radical differences in flood peaks from identical areas may 
be handled by using "equivalent" areas in the input data.

Area factors are best determined from-analysis of flow records from a large number of nearby stream gages (p.22). Where this data is unavailable, the Stanford Watershed Model may be applied to a range of typical areas (1B, pp. 69-73).

Urbanization and Channelization Factors: Both urban development and channel improvement within the tributary area increase flood peaks. Urbanization increases impervious area, reduces overland flow lengths, and reduces soil moisture storage. Channelization speeds runoff travelling downstream through the channel and reduces the volume of channel storage. Qualitative analysis of the hydrologic cycle indicates both effects would magnify flood peaks while urbanization would increase total runoff volume as well.

A quantitative analysis of these effects was based on 22 years of recorded streamflows from the Pond Creek watershed near Louisville, Kentucky. During this period, urban development multiplied by a factor of about six and almost 18 miles of improved channels were constructed. Actually, there are many kinds of urban development and many degrees of channel improvement. Each variation has its own distinct hydrologic effects. However, based on the approach of a previous study (2E), both were defined on a with or without basis. Urbanization was defined as the fraction of the tributary area in any kind of urban land use. Channelization was defined as the fraction of the tributary channel length improved to a prismatic cross section on a straight alignment.

The Stanford Watershed input parameters and representative watershed values of urbanization and channelization were determined for the first three and the last three years of the 22-year record (1B, pp. 27-28). Very significant changes were noted and used to establish relationships among the parameters, urbanization, and channelization. From the relationships, parameters could then be selected appropriate 
to the full range of possible combinations of urbanization and channelization for synthesizing for any desired point a long-term flow sequence which could be used for estimating flood peaks by frequency. The variation of flood peaks of a prescribed frequency with urbanization and channelization then provided a basis for computing factors to adjust flood peaks from natural areas containing no improved channels to peaks for the combination of urbanization and channelization existing in a particular watershed (1B, pp, 57-62).

The approach assumes urbanization and channelization will have homogeneous effects on flood peaks in the various subwatersheds in a given study area and that the effect is independent of total tributary area. In cases where hydrologic studies have shown signifi- i cently different hydrologic effects within the study area, adjusted "effective" urbanization values may be used in the computer analysis (1A, pp. 123-124).

The hydrologic effects of urbanization and channelization both vary with local climatic and watershed surface conditions . Urbanization tends to decrease the effectiveness of the soil surface in dampening floods by absorbing precipitation and thus is most effective in increasing runoff in arid areas underlain by deep pervious soils where soil surface action is relatively most important. Channelization tends to speed runoff and reduce channel storage and thus is most effective in increasing flood peaks in basins with small natural channels and overbank storage spread over large flat areas.

While a general relationship between the effect of urbanization and channelization on flood peaks and local watershed conditions could not be achieved in this one study, quantitative data was derived showing the effect of urbanization to be significantly greater in arid California than in humid Kentucky and the effect of channelization to be significantly greater in an area containing many natural swamps than in a better drained area (1B, pp. 54-62). 


\section{FLOOD HYDROGRAPHS}

Whenever reservoir storage is being considered as a flood control alternative, a complete flood hydrograph is needed for routing purposes because a reservoir achieves its effectiveness by modifying the hydrograph shape. The approach used in the analysis was to generate a flood hydrograph as a function of frequency and the size, urbanization, and channelization of the tributary area.

The most upstream hydrograph is routed through the reservoir and then one by one through the various channel reaches proceeding downstream. The routing is a function of channel improvement in the reach. At each point, the routed hydrograph is combined with the generated local inflow hydrograph before continuing downstream. The flood frequency relationship within the planning unit is determined from the peaks of floods of two or three different frequencies.

The hydrograph from a selected drainage area is generated from a predicted peak, volume, and time to peak and a set of possible hydrograph shapes (1B, pp. 41-87). The volume is stated as an average flow over the hydrograph duration. It is estimated using the same procedure described above for flood peaks from empirical relationships derived using hydrographs generated by the Stanford Watershed Model. A basic unit area average flow is corrected for drainage area, urbanization, and channelization. Specific empirical relationships were derived for two locations (Louisville, Kentucky, and Sacramento, California.) Hydrograph rising time was defined as the duration from the beginning of the hydrograph rise to the peak. It was found to significantly exceed the basin time of concentration because it includes the storm buildup period, the length of time from the beginning of excess rainfall to the rainfall of maximum intensity (1B, p. 52). Rising time is estimated for any specific area from unit area rising time, drainage area, and channelization. Urbanization was not found to be a significant influence. Total hydrograph base time within a particular study 
area may be taken as a constant multiple of rising time. Again, specific multipliers were derived for the two locations.

The final data needed for hydrograph development was a series of normalized hydrographs ranging from very sharp to very flat and indexed by the ratio of average flow to peak flow. Such hydrographs were developed from a large number of observed hydrographs of many shapes.

The hydrograph is generated from the input data by entering with a known drainage area, urbanization, channelization, and frequency. The flood peak is estimated as the product of a unit-area peak, the area, an area factor, and a channelization and urbanization factor (p.21). The average flood flow is estimated by the same process but using a different set of numerical values. The time to peak is estimated at the product of a unit-area time, an area factor, and a channelization multiplier. A normalized hydrograph is interpolated based on the resulting average to peak flow ratio. It is converted to an actual hydrograph by multiplying times by the time to peak and flows by the peak flow (1H, pp. 84-92).

Hydrographs are routed downstream by the Muskingum method based on read values of $\mathrm{K}$ and $\mathrm{x}$ for each channel reach $(1 \mathrm{H}, \mathrm{p}, 50)$. The routing coefficients may be varied according to whether or not a specific channel reach is improved during a particular stage.

THE STANFORD WATERSHED MODEL

Completion of the required hydrologic studies necessitated development of a working version of the Stanford Watershed Model (2B) in Fortran IV for use on the IBM 360/50 system at the University of Kentucky Computing Center. In an effort supported in part by funds provided through the University of Kentucky Research Foundation and with the help of the Computing Center staff, Stanford Watershed Model III (3A, pp. 84-101) was translated into Fortran IV. Shortly thereafter, Stanford Watershed Model IV was completed (2B). Certain 
features of the revised model were incorporated into the translation. Others were not: Omitted features are primarily those dealing with plotting of daily flows, combining basins in sequence, and using multiple recording gages for a single basin (1E).

As the research progressed, it became desirable to make various adjustments and add several additional optional features to the Fortran. Most of these had to do with rearranging and expanding the printout. Others provided nonlinear channel routing by permitting the option of making routing time proportional to stream velocity, separated overland flow routing of impervious from pervious areas, varied daily evaporation with rainfall, and varied the channel storage routing constant between flow confined to the channel and flow extending into the flood plain. However, the basic interloop for dealing with the interaction between precipitation and the soil surface is basically identical to that of Stanford Model IV.

\section{PROGRAM APPLICATION}

A digital computer program for flood control planning is essentially a tool to help those making policy or planning decisions. As a tool, it can of itself not prescribe the relative merit of decision alternatives. It can say that if the input data properly describes the situation and if the programmed analysis represents an acceptable design procedure, certain courses of action are to be preferred over others. A more thorough analysis is always possible through obtaining better data or refining the program.

\section{POTENTIAL APPLICATIONS}

The planning programs can contribute to research, planning, and design of alternative flood control measures in many ways. Design Standards: Design standards should not be regarded as a firm and absolute physical requirement independent of cost. Engineered design deals in probabilities. For example, a slightly steeper channel 
side slope, slightly increases the probability of bank sloughing and hence expected maintenance cost. A slightly flatter side slope does not eliminate the possibility, it only reduces the probability. The proper design standard can only be developed through an analysis of the effect of alternative standards on overall cost. A simple cost estimate for channels designed with varying side slopes is insufficient because of the possibility of a higher standard shifting the optimum combination of measures. By varying the input data to the planning programs, the consequences of alternative design standards become readily available for consideration. The engineer can no longer excuse arbitrarily selected standards on the grounds that detailed analysis is too time consuming.

Sensitivity Studies: Many of the input data parameters are of a controversial nature (discount rate (3D, pp. 37-45) and the value of open space in urban areas for example). Others are difficult to measure (the tractive force at incipient soil erosion and dam foundation conditions for example). The planner needs to determine whether the optimum flood control program is sensitive to the values used for these parameters. Unless it is, there is no need to spend valuable planning time zeroing in on a precise value. A representative value will be adequate. A group of measures will be better accepted if it can be shown to be optimum at all discount rates between $\underbrace{3.0}$ and 7.0 rather than if it can only be stated as the best for a rate of 3.25 percent. Sensitivity studies permit considerable saving in data gathering for project formulation and allow effort to be more effectively spent in seeking more critical data. Repeated computer runs can be used to complete sensitivity studies in any desired detail.

Research Guidance: Many questions remain to be answered on the evaluation of flood damages and the design and economic analysis of nonstructural measures for flood control. Research is continuing into many of these areas. However, it may be difficult to tie the contribution 


\section{APPLICATION EXPERIENCE}

Part of program development was to apply the programs to specific problem areas as a means of ensuring that reasonable results were produced in actual situations, of observing what kinds of measures were most applicable in specific settings, and of analyzing the sensitivity of program results to specific input variables. Four problem areas were studied.

Morrison Creek Watershed, Sacramento County, California: The Morrison Creek watershed drains 134 square miles in rapidly growing urban area along the southern fringe of Sacramento. The land is below average quality for agriculture and all fairly flat. Flooding is distinctly seasonal, and peaks for a given frequency are low in the arid climate (18 inches annual rainfall). Reservoir storage was not a feasible flood control alternative.

The flood hazard throughout the watershed had been previously evaluated $(2 \mathrm{C})$, and the results were used to verify the initial computer programming $(1 G)$. The study indicated a time variant flood control program combining all three kinds of measures. Pond Creek Watershed, Jefferson County, Kentucky: The Pond Creek watershed drains 72 square miles in a rapidly growing urban area along the southern fringe of Louisville. The flood plain is quite flat, was once a swamp, was originally provided a network of drainage ditches, and has recently undergone more extensive channel improvement. The climate is more humid (44 inches annual rainfall), and flood peaks are spread throughout the year (1B, pp, 10-22). Again, no reservoir storage was applicable.

The study indicated a time variant flood control program combining further channel improvement and land use management. Flood proofing did not prove feasible because of the intensity of urban development and the relatively infrequent flooding (1B, pp. 114-142). 
Licking River Watershed, Harrison County, Kentucky: The Licking River upstream from Falmouth, Kentucky, drains 927 square miles of rolling farm land including two towns, both located along the river, exceeding 1000 population. The flood plain contains some of the best farm land, but many acres of good land are scattered throughout the watershed. The study was centered around the Hinkston Creek damsite where a reservoir was studied but not justified by the U.S. Army Corps of Engineers.

The study also failed to justify flood storage at the Hinkston Creek reservoir site under present conditions; however, at presently projected urban growth rates justification in about 20 years was indicated. (1H, pp. 104-132). Channel improvement was currently justified through the two towns on the river (Cynthiana and Falmouth). Land use management was found optimum in several of the more rapidly growing communities, and flood proofing was found to be economical for many scattered buildings in rural areas. North Fork of the Kentucky River Watershed, Perry County, Kentucky: The North Fork of the Kentucky River upstream from Haddix at the mouth of Troublesome Creek drains 649 square miles (1A). The watershed contains steep mountain slopes with the only flat land and hence both farming and urban development forced into the flood plain. The population of the area as a whole has been declining for years, but flood-plain population has been more stable. Income levels are very low compared with the national average. The study considered the Carr Fork Reservoir currently nearing completion by the Corps of Engineers and two additional sites, Cornettsville and Kingdom Come, currently being studied.

The study justified the use of flood storage in Carr Fork Reservoir but in a smaller amount than that to be provided. Additional flood control storage was found more economical at the Cornettsville that at the Kingdom Come site but it could be justified only on an 
incremental basis. The overall justification of the Cornettsville Reservoir would require substantial benefits from recreation, low flow augmentation, and other non-flood-control purposes. Channel improvement was not found to be economically justified. Land use management is not an effective measure in areas with declining population. Flood proofing was found economical in most of the flood plain and is currently practiced in varying degrees by many residents (1A, 194-196).

\section{SENSITIVITY STUDIES}

A number of sensitivity studies were performed in order to better evaluate the economic advantage of the various measures under alternative conditions. The results provided an important supplement to the four case studies in better understanding when and where particular measures are most applicable. Such studies were performed on each of the four watersheds by holding all the input data constant except for one variable at a time (1G, pp. 78-116; 1B, pp. 114-132;1H, pp. 104-131; 1A, pp. 184-196). Study findings include:

1. Except in areas planted to high value crops subject to growing season or very frequent flooding, channel improvement requires a level of urban development inversely related to flood severity for economic justification. The milder the flooding, the more urban benefits are required for justification (1C, p. 337).

2. Flood proofing is most applicable to scattered buildings frequently flooded. Dense development produces economies of scale favoring structural measures. Infrequent flooding does not seem to justify the cost of maintaining a ready flood proofing program over the long periods between floods (1C, pp. 337-338).

3. Land use management is not needed in rural areas under little or no pressure for urban development and is not effective in already densely developed urban land. The range of applicability was from 2 to 75 percent urban in the land adjacent to the flood plain. 
The upper end of the range increased with flood severity. Unless structural measures were particularly costly, the termination of the land use control would normally coincide with channel improvement (1C, p. 338).

4. Reservoir flood storage is easiest to justify where the reservoir controls a large portion of the area tributary to a flood plain suffering severe flood loss or when it functions as one of a system of reservoirs controlling in aggregate a large portion of the tributary area. Isolated reservoirs controlling small areal fractions are relatively ineffective.

5. A combination of two or more of the alternative measures may be optimum. Channel improvement may be used in conjunction with an upstream reservoir and be supplemented by land use control to restrict new development from low lying land subject to residual flooding and flood proofing to protect scattered existing buildings.

6. Structural measures were found to be the only economical flood control alternative in highly developed urban areas. Their use was generally a much more important component of reducing total cost (Eq. 1) than was the use of non-structural measures. Overall program cost was more sensitive to parameters affecting structural than nonstructural measure cost (1C, pp. 339-343).

7. The early purchases and holding of right-of-way was found to be an essential part of planning a channel improvement program in a growing urban area. As a general rule, purchase should occur when about 2.0 percent of the surrounding land is in urban use (ID).

\section{RESEARCH NEEDS}

Without a doubt, computerized planning opens the door to a quicker, more thorough analysis of flood control alternatives. As a byproduct, it pinpoints those issues where further research and introspection of comparative values are most needed to produce a more effective program. More pressing research needs include: 
1. More detailed analysis of the comparative economic advantage of alternative flood proofing measures. Continuing studies should focus on consideration of particular measures for particular conditions with adjustments to flooding developed in frequently flooded areas providing a starting point for data collection.

2. More detailed analysis of the comparative economic advantage and damage related to flood plain location for particular types of urban development. As is the case with flood proofing, planning based on averages needs to be refined to planning based on particulars.

3. Better information on the variation of flood hydrograph peak, volume, and shape with urbanization and channelization in the tributary area. The information is important in any flood planning for the small watercourses through urbanizing areas. The whole hydrograph will become more frequently needed as storage alternatives are increasingly employed to minimize adverse downstream effects of channel improvement.

4. Incorporation of the effects of channel storage, alignment, and density into procedures for predicting flood peaks from small drainage areas.

5. A method to arrive at a computer selected set of Stanford Watershed Model input parameters of best fit without the necessity of subjective trial and error adjustment. Such a procedure would be particularly helpful in better evaluating the effects of urbanization and channelization on flood hydrographs.

6. Extension to multipurpose projects. The programs evaluate only flood control measures in a day when it is necessary to consider effects on other water resource development while planning for any single purpose. Such effects are currently brought into the program through the input data. As computers of greater speed and storage capacity are developed, a multipurpose planning program will become possible. 
7. Extension to multi-reservoir systems. Similarly, the programs can consider only one reservoir at a time. Reservoir systems for flood control can be evaluated only by a planned sequence of computer runs (1A, pp. 4l-43). A single multi-reservoir planning program will also become feasible as new computing systems are developed.

8. Bringing reservoir construction more into the dynamic analysis. The programs currently figure the optimum time of reservoir construction. They do not consider the possibility of stage construction or early right-of-way purchase for reservoirs.

\section{PROGRAM AVAILABILITY}

The computer programs developed through this research project will accomplish little unless they are used. Those involved in flood control planning will naturally have a number of questions. How can the programs be obtained? Do they use criteria and procedures acceptable to my agency? Can they be adopted to the computer facilities I have available? What types of input data are required and how difficult are they to obtain? How should the computer runs be organized to evaluate specific situations? What is the proper interpretation of the output?

A used large computer program is a dynamic entity. It must be constantly changing in response to the needs of particular investigators or the nature of particular flood problems being studied. Research advances continually provide more refined approaches. All three programs are periodically being updated as part of a continuing program of research and instruction. While listings of the Stanford Watershed Model (2B), the University of Kentucky Flood Control Planning Program II for use where storage is not to be considered ( $1 \mathrm{~A})$, and the University of Kentucky Flood Control Planning Program III for considering storage $(1 \mathrm{H})$ are all published, the potential user would be ahead to contact the Principal Investigator for the current listing and Fortran card deck. 
The programs have all been extensively used and debugged, but those applying them to new and different situations may still encounter difficulty. Others may wish to change the programming in accordance with specific local conditions or agency policies. The help of the Principal Investigator is also available for this purpose.

All three programs are written in Fortran IV based on the G compiler for the $360 / 50$ system. Storage requirements are for the Kentucky Watershed Model (Version of May 23, 1968) 99,406 bytes, for Program (Version of June 29, 1968) 85,454 bytes, and for Program III (Version of July 8,1968$) 139,926$ bytes.

The required input data for both planning programs are described in detail by Cline ( $1 \mathrm{~A}, \mathrm{pp}, 49-155)$. So is the resulting output ( $1 \mathrm{~A}$, pp. 156-184). Similar published information is available for the watershed model (1E, 2B). While some of the details change with new program refinements, the basic input and output is expected to remain similar.

For flood plains where reservoir storage is not to be considered, the entire analysis can be made on one run with Program II except to the degree sensitivity studies are desired. For flood plains where only one feservoir site is to be considered, one run with Program II is required for measure planning within subwatersheds not along the watercourse downstream from the site. Program III can then analyze the reservoir and downstream subwatersheds in one run. Computer time varies greatly depending on the options selected for study (IA, pp. 57-6I) and the number of viable alternatives per subwatershed-stage. Encountering many alternatives of nearly equal economic merit greatly lengthens running time.

For flood plains where two or more reservoir storage sites are to be considered, the analysis can be completed through a maximum of two runs per site (1A, pp, 41-43). The first series of one run per reservoir assumes no other reservoirs (except those already existing) are in place, eliminates the worse reservoirs from further consideration 
and ranks the better ones according to net benefits achieved. The second series begins with the highest ranked site, assumes all existing and higher ranked reservoirs are in place, and continues down the list until storage at additional sites cannot be justified.

While net benefits and benefit-cost ratios are not explicitly printed in the output, both may be readily determined. For planning block measures, flood damage with no measures is printed if requested (1A, pp. 158-161). That with the optimum combination of measures is also printed along with implementation cost by measure. The net benefit is the reduction in damage. Some form of benefit allocation must be used where benefits by measure are desired and more than one measure is employed.

For reservoirs, the flood-plain cost (Eq. I summed for all downstream subwatersheds) and the benefit downstream from the formal study area are printed (1A, pp. 181-182). Reservoir benefit is the net reduction in flood-plain cost effected by the reservoir plus the downstream benefit. Reservoir cost is printed (1A, pp. 177-178).

\section{CONCLUSION}

The computer programs developed through this research project potentially provide a valuable contribution to better economic analysis of flooding problems and more widespread use of non-structural measures. The potential will only be achieved as the programs are used and as they are adapted to specific problems confronting planning agencies. Any suggestions, modifications, or refinements the reader may have will be appreciated. Any help the Principal Investigator can give will be gladly extended. 


\section{LIST OF REFERENCES}

The following references fulfill much the same function as does the body of the report. It includes publications based on project research, major references used in research development, and other references specifically used in the text. It is not intended to duplicate the many related references found at the end of the five more detailed reports.

\section{LIST OF PROJECT PUBLICATIONS}

1A. Cline, James Norris. Planning Flood Control Measures by Digital Computer. Lexington, Kentucky: University of Kentucky, Water Resources Institute, Research Report No. 11,1968 .

1B. Dempsey, Clyde R. The Effects of Geographical and Climatic Setting on the Economic Advantages of Alternative Flood Control Measures. Lexington, Kentucky: University of Kentucky, Water Resources Institute, Research Report No. 10,1968 .

1C. James, L. Douglas. "Economic Analysis of Alternative Flood Control Measures," Water Resources Research, Vol. 3, No. 2 (Second Quarter, 1967), pp. 333-344.

1D. James, L. Douglas. "Preservation of Right-of-Way for Public Facilities," Proc. of American Society of Civil Engrs, Vol. 93, No. UP4 (December, 1967), pp. 243-255.

IE. James, L. Douglas. "Use of the Digital Computer to Analyze Hydrologic Proglems," Proc. Of Fifth Annual Sanitary and Water Resources Engineering Conference, Nashville, Tennessee: Vanderbilt University, Department of Civil Engineering, June, 1966, pp. 37-58.

1F. Miller, Carlos Fix. Evaluation of Runoff Coefficients from Small Natural Drainage Areas, Lexington, Kentucky: University of Kentucky, Water Resources Institute, Research Report No. 14, 1968.

1G. Rachford, Thomas M. Economic Analysis of Alternative Flood Control Measures by Digital Computer. Lexington, Kentucky: University of Kentucky, Water Resources Insitute, Research Report No. 1, 1966. 
1H. Villines, James Ray. Economic Analysis of Flood Detention Storage by Digital Computer. Lexington, Kentucky: University of Kentucky, Water Resources Institute, Research Report No. $9,1968$.

\section{LIST OF MAJOR REFERENCES}

2A. Clarke, K. D. Application of Stanford Watershed Model Concepts to Predict Flood Peaks for Small Drainage Areas. Lexington, Kentucky: Kentucky Department of Highways, Division of Research, January, 1968.

2B. Crawford, Norman H. and Ray K. Linsley. Digital Simulation in Hydrology: Stanford Watershed Model IV. Stanford, California: Stanford University, Department of Civil Engineering, Technical Report No. 39, July, 1966.

2C. James, I. Douglas. A Time-Dependent Planning Process for Combining Structural Measures, Land Use, and Flood Proofing to Minimize the Economic Cost of Floods. Stanford, California: Stanford University, Institute in Engineering-Economic Systems, Report EEP-12, August, 1964.

2D. James, L. Douglas, "Non-Structural Measures for Flood Control," Water Resources Research, Vol. 1, No. 1 (First Quarter, 1965), pp. 9-24.

2E. James, L. Douglas. "Using a Digital Computer to Estimate the Effect of Urban Development on Flood Peaks," Water Resources Research, Vol. 1, No. 2 (Second Quarter, 1965), pp. 223-234.

2F. Sheaffer, J. R. Flood Proofing: An Element in a Flood Damage Reduction Program. Chicago, Illinois: University of Chicago, Department of Geography, Research Paper No. 65, 1960.

2G. Task Force on Federal Flood Control Policy. A Unified National Program for Managing Flood Losses, House Document No. 465, 89 th Congress, 2nd Session, Washington: U.S. Government Printing Office, 1966.

2H. U. S. Congress Senate. Policies, Standards, and Procedures in the Formulation, Evaluation, and Review of Plans for Use and Development of Water and Related Land Resources. Senate Document No. 97, 87th Congress, 2nd Session. Washington: U.S. Government Printing Office, 1962 . 


\section{LIST OF OTHER RELATED PUBLICATIONS}

3A. Anderson, Eric A. and Norman H. Crawford. The Synthesis of Continuous Snowmelt Runoff Hydrographs on a Digital Computer. Stanford, California: Stanford University, Department of Civil Engineering, Technical Report No. 36. June, 1964 .

3B. Kates, Robert W. Hazard and Choice Perception in Flood Plain Management. Chicago, Illinois: University of Chicago, Department of Geography, Research Paper No. 78, 1962.

3C. U. S. Army Corps of Engineers, Office of the Chief of Engineers, "Survey Investigations and Reports: Treatment of NonStructural Alternatives," Circular No. 1120-2-40. Washington, D.C., April, 1968.

3D. Whipple, William, Jr. Economic Basis for Water Resources Analysis. New Brunswick, New Jersey: Rutgers University, Water Resources Research Institute, June, 1968. 